\title{
DEFINITIONS OF USEFUL ENERGY AND TEMPERATURE AT THE OUTLET OF SOLAR COLLECTORS
}

\author{
Shakhnoza Sultanova ${ }^{1}$, Jasur Safarov ${ }^{2}$, Azamat Usenov $^{3}$, Tojiniso Raxmanova ${ }^{4}$ \\ ${ }^{1}$ Tashkent State Technical University, Department technology services, University - 2, \\ Tashkent, 100095, Uzbekistan \\ 2 Tashkent State Technical University, Department technology services, University - 2, \\ Tashkent, 100095, Uzbekistan \\ ${ }^{3}$ Tashkent State Technical University, Department technology services, University - 2, \\ Tashkent, 100095, Uzbekistan \\ ${ }^{4}$ Tashkent State Technical University, Department technology services, University - 2, \\ Tashkent, 100095, Uzbekistan \\ ${ }^{5}$ Tashkent State Technical University, Department technology services, University - 2, \\ Tashkent, 100095, Uzbekistan
}

\begin{abstract}
The article examines the solar collector of a solar water heating dryer using the example of drying ginger root (Zungiber). The diagram of a solar water heating drying unit is presented. The useful energy and temperature coming from the solar collector were analyzed using the model. The graphs are compared with the experimental results.
\end{abstract}

\section{Introduction}

Solar energy hits our planet in just 8 minutes and 20 seconds after it left the giant furnace, the Sun, which is located at a distance of $1.5^{*} 10^{11} \mathrm{~m}$. The Sun has an effective black body temperature of $5762 \mathrm{~K}$. The temperature in the central region is much higher and estimated from $8 * 10^{6}$ to $40^{*} 10^{6} \mathrm{~K}$. In fact, the Sun is a reactor with continuous fusion, in which hydrogen is converted into helium. The total energy generated by the sun is $3.8 * 10^{20} \mathrm{MW}$, which corresponds to 63 $\mathrm{MW} / \mathrm{m}^{2}$ of the sun's surface. This energy is radiated outward in all directions. Only a tiny fraction of $1.7 * 10^{14} \mathrm{~kW}$ of all emitted radiation is intercepted by the ground. However, even with this small fraction of 30 minutes of solar radiation falling to the ground, it is equal to the global energy demand for one year $[1,2]$.

All forms of energy in the world as we know it are of solar origin. Oil, coal, natural gas, and wood were originally produced through photosynthetic processes accompanied by complex chemical reactions in which decaying vegetation was exposed to very high temperatures and pressures for extended periods of time. Even the energy of wind and tides is of solar origin, as they are caused by differences in temperature in different regions of the Earth [1].

The biggest advantage of solar energy over other forms of energy is that it is clean and can be supplied without any pollution. Over the past century, fossil fuels have provided most of our energy because they are much cheaper and more convenient than energy from alternative energy sources, and until recently environmental pollution was not a major concern [1].

\subsection{Using a solar water heating dryer}

Several industrial heat demand studies have identified several industrial sectors with favorable conditions for the use of solar energy. The most important industrial processes using heat at a medium temperature are: sterilization, pasteurization, drying, hydrolysis, distillation and evaporation, rinsing and cleaning, and polymerization. Some of the most important processes and the range of temperatures required for each of them are described in [1-6].

A number of scientific papers on this issue have been presented by a number of researchers recently, Norton B. [5] presented the most common industrial heat applications. In particular, the history of the application of solar industrial and agricultural processes was presented and practical examples were described [1].

A solar process heat system for decentralized applications in developing countries was presented by F. Spate et al. [6]. The system is suitable for communal kitchens, bakeries and post-harvest handling. The system uses a fixed focus parabolic collector, high temperature flat collector and pebble oil storage [1].

Benz N. et al. [7] presented the planning of two solar thermal systems producing process heat for a brewery and a dairy plant in Germany. In both industrial processes, solar outputs were found to be 
comparable to solar system outputs for domestic solar water heating [1].

The development of a solar dryer is to supply the product with more heat than is available under ambient conditions, sufficiently increasing the vapor pressure of the moisture retained in the culture, thereby enhancing the migration of moisture from within the culture and greatly reducing the relative humidity of the drying air, thus increasing its ability to retain moisture and providing a sufficiently low equilibrium moisture content [1].

The purpose of this study is to develop and experimentally investigate a model of a solar water heating drying plant for drying ginger (Zingiber) root and other medicinal plants. There are models available for the individual subsystems of the drying system, however, there is currently no complete system model for controlled, defined helio drying for ginger (Zingiber) root and other medicinal plants [8-11].

The installation consists of a transparent solar flat collector, drying chamber with trays and an exhaust pipe. The unit was developed and tested for drying ginger root (Zingiber). In fig. 1 shows a simple diagram of a solar water heating dryer. Environmental data were entered into the system model. Temperature, relative humidity and heat flux in the solar water heating dryer were monitored to obtain an accurate model [9].

This model of solar water heating dryer will provide a tool to predict the performance of the drying system for ginger (Zingiber) and other medicinal plants in various climatic conditions, optimize the design and operation of the solar water heating dryer and explore alternative concepts for the entire system [10-18].

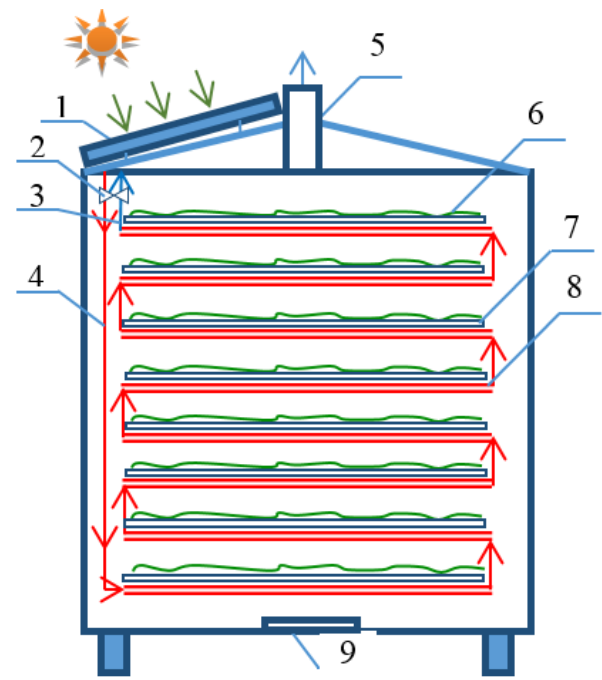

Fig. 1. Diagram of a solar water heating drying plant 1-solar collector; 2-pump for water circulation; 3 -water in the collector; 4-hot water from the collector; 5-exhaust pipe; 6-

products; 7-pallet; 8-pipe for water; 9-air inlet.

\subsection{Solar collector model}

The solar collector model determines the outlet temperature and relative humidity, ambient temperature and relative humidity. In fig. 2 . Shows the location of MATLAB in more detail.

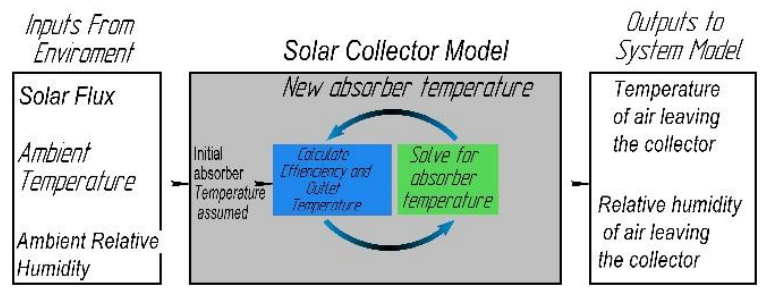

Fig. 2. Scheme of the solar collector

The expression for the efficiency of a stationary solar collector with a developed structure is presented in the form:

$$
\eta=\frac{\alpha_{\text {солн. }}}{1+\frac{h_{r}}{\epsilon \rho C_{p} V_{\mathrm{B}}}}
$$

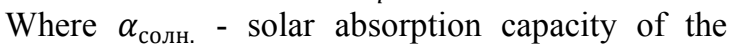
absorber surface; $h_{r}$ - coefficient of radiation heat losses from the surface of the absorber to the environment; $\epsilon$ - efficiency of heat exchange of the collector surface; $V_{\text {в }}$ - absorption rate; $\rho$ - air density; $C_{p}$ is the specific heat of air.

Suction rate equation:

$$
V_{\mathrm{B}}=\frac{\dot{V}}{A_{\mathrm{K}}}
$$

where $V$ is the volumetric flow rate of the system; $A_{\mathrm{K}}$ - collector surface area. The equation for $h r$ is:

$$
h_{r}=\varepsilon_{\Pi} \frac{\sigma\left(T_{\Pi}^{4}-T_{\infty}^{4}\right)}{T_{\Pi}-T_{\infty}}
$$

where $\varepsilon_{\text {п }}$ is the emissivity of the absorber plate; $\sigma$ Stefan-Boltzmann constant; $T_{\Pi}$ - plate temperature; $T_{\infty}$ - ambient air temperature.

The solar absorption of the plate and the emissivity of the plate are usually determined by independent measurement or the experimental data are fitted to the model equation (1). By fitting the experimental data to the efficiency model, the calculated values are: $\alpha_{\text {солн }}=\varepsilon p=0.687$ for the structure used in the system [12]. Extensive testing of the absorber material is required to provide greater confidence in the material properties. The plate temperature is also not known for this system. To determine the temperature, the initial temperature was assumed to be approximately $50^{\circ} \mathrm{C}$ higher than the ambient temperature, and the loop iteration was used until the temperature converged. The model for the plate temperature is assumed to be a target temperature higher than the collector outlet temperature (about $10^{\circ} \mathrm{C}$ ). The model started from the assumed initial temperature of the absorber and was repeated until the change in the absorber temperature between iterations became less than $0.01{ }^{\circ} \mathrm{C}$. Convergence criteria are user-defined to provide varying degrees of accuracy based on model requirements.To develop an efficiency model, we divide the overall efficiency into three components: efficiency at the front of the plate, through the holes in the plate, and at the rear of the plate. Equations (4-7) show the definition for each efficiency:

$$
\epsilon=\frac{T_{o}-T_{\infty}}{T_{\Pi}-T_{\infty}}
$$




$$
\begin{aligned}
\epsilon_{\Pi} & =\frac{T_{o 1}-T_{\infty}}{T_{\Pi}-T_{\infty}} \\
\epsilon_{\mathrm{o}} & =\frac{T_{o 2}-T_{o 1}}{T_{\Pi}-T_{o}} \\
\epsilon_{3} & =\frac{T_{o}-T_{o 2}}{T_{\Pi}-T_{o 2}}
\end{aligned}
$$

where $T_{o 1}$ is the average volumetric air temperature when it enters the hole; $T_{\infty}$ - ambient air temperature; $T_{\Pi}$ is the temperature of the absorbing plate; $T_{o 2}-$ average volumetric air temperature at the outlet from the hole; $T_{o}$ - average volumetric temperature of the inner part of the collector; $\epsilon_{\Pi}$ - efficiency for the front of the plate; $\epsilon_{\mathrm{o}}$-efficiency through the hole; $\epsilon_{3}$ efficiency on the back of the plate.

This temperature is shown in detail in Fig.3.

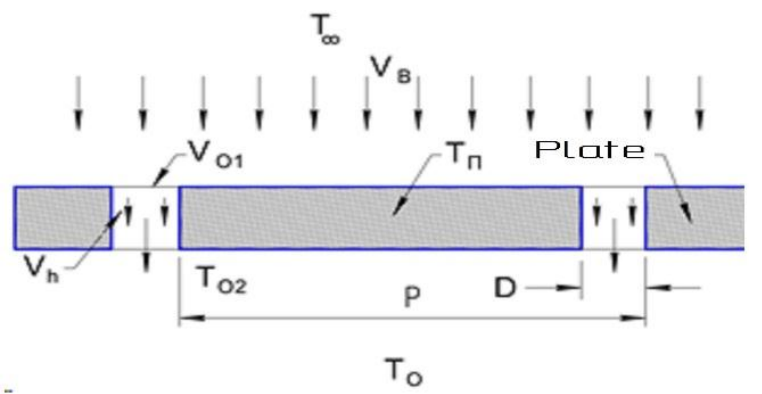

Fig.3. Diagram of the absorber plate for the model

Combining equations (4-7), the overall efficiency is:

$$
\epsilon=1-\left(1-\epsilon_{\Pi}\right)\left(1-\epsilon_{\mathrm{o}}\right)\left(1-\epsilon_{3}\right)
$$

We simulate each efficiency model based on the speed Reynolds number at each absorber stage. The model is based on empirical experience and the constants are solved by fitting the model to experimental data taken from a variety of different plate configurations. For efficiency in the front of the plate:

$$
\epsilon_{\Pi}=\frac{1}{1+R e_{s^{\mathrm{M} и н}}\left[a * R e_{w}^{-\frac{1}{2}}, f\right]}
$$

where $a$ and $f$ are constants and equal to 1.733 and 0.02136 , respectively; $R e_{s}$ is the Reynolds number based on the suction rate; $R e_{w}$ - Reynolds number based on wind speed [13].

The value for wind speed was accepted as there was no experimental data for wind speed on the test day.

The efficiency through the hole in the plate is shown as:

$$
\epsilon_{\mathrm{o}}=1-e^{-4\left(c \frac{P}{D}+\frac{3,66 t}{\operatorname{Pr} R e_{h} D}\right)}
$$

where $P$ is the pitch of the holes; $D$ is the diameter of the holes; $P r$ is the Prandlt air number; $R e_{h}$ is the Reynolds number based on the velocity through the holes; $\mathrm{t}$ is the thickness of the plate [13]. $c \frac{P}{D}$ takes into account the non-uniform temperature at the entrance to the hole in the absorber plate. The constant $\mathrm{c}$ was set to zero because the simulated transparent reservoir is so small that the hole efficiency is negligible.

Finally, the efficiency at the back of the plate is shown as:

$$
\epsilon_{3}=\frac{1}{1+e * R e_{b}^{\frac{1}{3}}}
$$

where $e=0.2273 ; R e_{b}$ - Based on the suction rate divided by the porosity of the plate [13]. Combining formulas (9-11) with equation (8) gives the overall reservoir efficiency, which is used to determine the reservoir efficiency using equation (1).

To determine the temperature leaving the manifold, a useful heat gain was found:

where $I_{c}$ is solar insulation.

$$
Q_{u}=\eta I_{c} A_{\mathrm{K}}
$$

Finally, the outlet temperature was found using:

$$
T_{\text {вых. }}=\frac{Q_{u}}{\dot{m} C_{p}}+T_{\infty}
$$

Equations (12) and (13) are widely used to determine the useful energy and temperature at the outlet of solar collectors.

\subsection{Results of the experimental study}

Two rounds of experimental data have been successfully obtained. Each stage was carried out in a complete drying chamber of the ginger root, which were dried for two days. These days were sunny with occasional very light winds. A longer period of cloud cover and stronger breezes occurred on the first day of the experiment. An error was introduced into the data due to breezes when measuring the weight of the trays.

\begin{tabular}{|c|c|c|c|c|c|c|c|c|c|}
\hline & Tray \# & 1 & 2 & 3 & 4 & 5 & 6 & 7 & 8 \\
\hline \multirow{2}{*}{ 泀 } & Initial Mass [kg] & 0,429 & 0,374 & 0,368 & 0,390 & 0,356 & 0,395 & 0,398 & 0,408 \\
\hline & Initial MC_wb & $73,2 \%$ & $71,4 \%$ & $71,7 \%$ & $73,3 \%$ & $73,0 \%$ & $70,6 \%$ & $72,4 \%$ & $73,5 \%$ \\
\hline \multirow{2}{*}{ 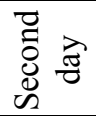 } & Initial Mass [kg] & 0,435 & 0,387 & 0,385 & 0,386 & 0,430 & 0,444 & 0,444 & 0,441 \\
\hline & Initial MC_wb & $72,9 \%$ & $71,8 \%$ & $71,9 \%$ & $73,6 \%$ & $72,8 \%$ & $72,5 \%$ & $73,0 \%$ & $72,3 \%$ \\
\hline
\end{tabular}
To minimize this error during the second experimental test, a heavy cooking tray was used as a base on the balance to make the trays more stable during weighing.

The ginger roots were cut into $0.5 \mathrm{~cm}$ thick slices and placed on trays in the setting. The starting weight and moisture content for each pallet can be found in Table1.

Table 1. Initial weight of ginger root and moisture content by pallets

After the experimental data was collected and processed, and the modeling was completed, the results were compared to validate the model and highlight potential system improvements. The parameters were iterated to better fit the model to the data. Below are the final results of experimental and simulated data. 


\subsection{Experimental conditions and plant performance}

The first phase of the collected data had a large uncertainty in moisture content values due to timing and less favorable weather conditions and, therefore, was not fully analyzed. Figures 4 and 5 show temperature data collected during testing for both experiments. The three collector temperatures were averaged to find the collector outlet temperature that was used to calculate the collector efficiency. The thermocouple after the sump was located immediately after the tray, and the entrance to the chimney was located just before the entrance to the circular chimney. In the figure, data is a collection of discrete data points; connecting lines are used for clarity. $T_{3}$ was the thermocouple closest to the absorbent plate, so it makes sense that this is the highest temperature of the collector outlet temperature sensors. For comparison of data, $T_{2}, T_{4}$ were averaged to obtain the outlet temperature from one collector.

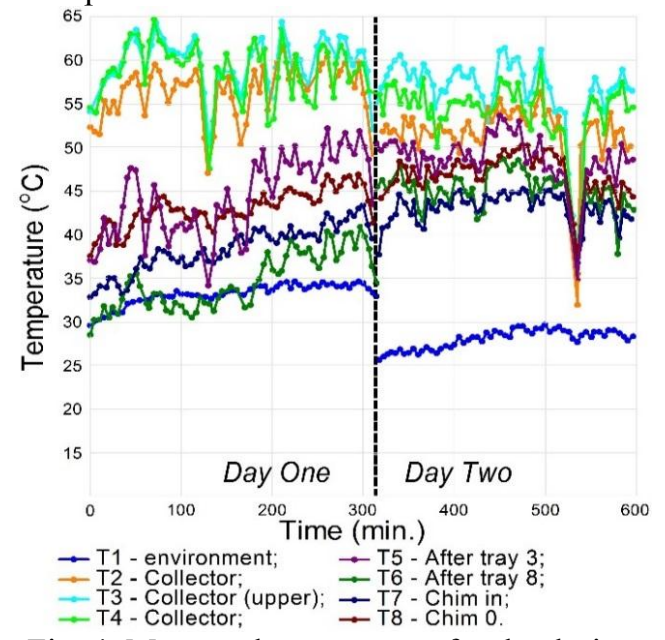

Fig. 4. Measured temperature for the drying experiment from the first day and the second day

In fig. The 5 first few data points for T8 are outliers because the thermocouple was turned off at the start of the experiment and reads -9999 when it does. The same trends are seen in the second data phase as the first. The collector outlet regularly exceeded the ambient temperature by $20{ }^{\circ} \mathrm{C}$.

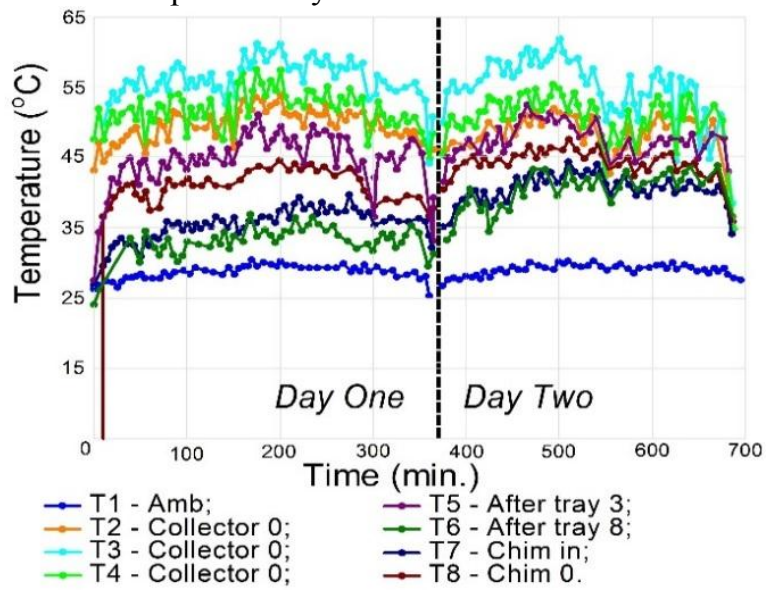

Fig. 5. Measured temperatures for experimental drying on the first day and the second day
Fig. 6 shows the efficiency of the collector over time. Efficiency mostly stays between $40 \%$ and $70 \%$, however there are a few emissions. Most of them are associated with the fact that the system has a heat accumulator, but a steady state model was adopted. When a cloud or other object blocks the sun for a short time, the solar flux decreases very quickly. However, the temperature in the system does not decrease as quickly due to the thermal mass of the system. This results in high temperatures reported for low solar fluxes. This especially explains the last point, which exceeds $100 \%$ efficiency. This also explains the low efficiency for a couple of pips in the period.

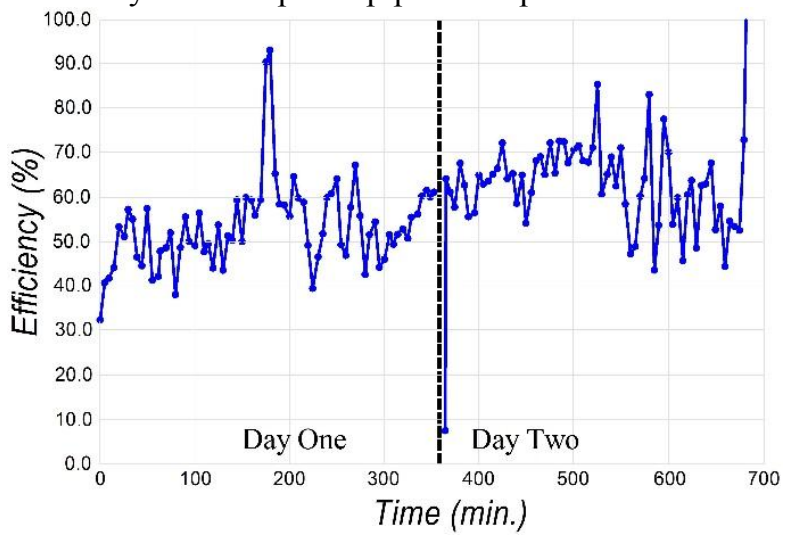

Fig. 6. Collector efficiency versus time for day one and day two

On the whole, the collector efficiency regularly exceeded $50 \%$ with an average temperature rise of over $20^{\circ} \mathrm{C}$. The dryer actively added moisture during the entire drying process, which was manifested in an increase in the air humidity coefficient. Since the first dataset did not have ideal environmental conditions and the lead times between experiments were significantly longer than overnight, the second dataset was the main analysis and modeling.

In the following graphs, all experimental data are taken from the experiment conducted on the first day and the second day. Discrete data points represent experimental values, while continuous function shows simulated data. Simulations are technically discrete data at five minute intervals. The line is used for clarity. In fig. 7 shows a comparison of experimental and simulated temperature data at the manifold outlet.

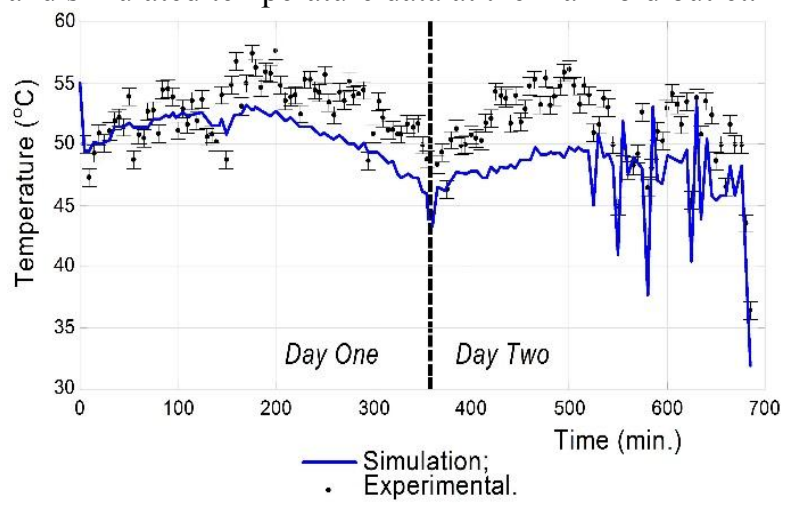

Fig. 7. Comparison of collector outlet temperature 
The collector model underestimates the collector outlet temperature according to our experimental data.

This slightly overestimates the flow rate, which can lead to overestimation during drying. In fig. 8 shows the results of reservoir efficiency.

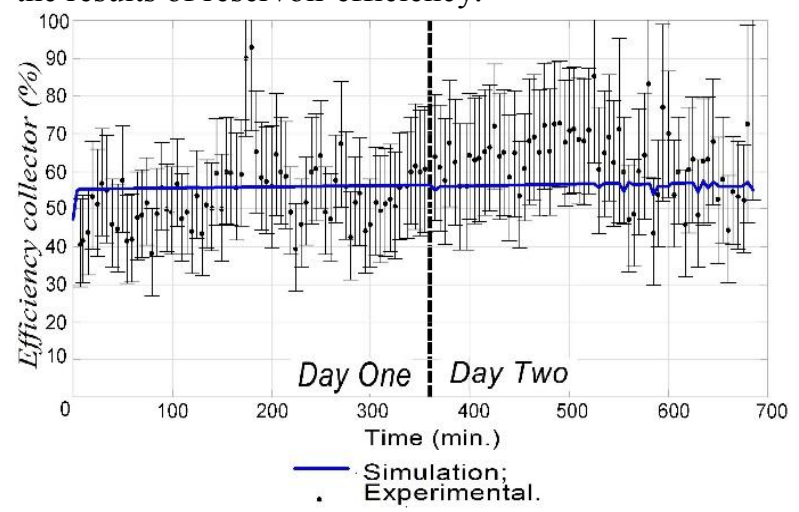

Fig. 8. Collector efficiency

\section{Conclusion}

The principle and model of solar collector operation are analyzed. The reservoir efficiency model predicts efficiency well in relation to the average efficiency observed in the experimental data. The efficiency is expected to be more dependent on temperature and flow. When using experimental flow rates, simulations show a large variance over time. The amplification of the flow pattern can have a large effect on the entire system, since each subsystem is dependent on the volumetric flow rate.

\section{References}

1. Kalogirou S.A. Solar thermal collectors and applications. Progress in Energy and Combustion Science. №30, 2004. №231-295.

2. Kreith F., Kreider J.F. Principles of solar engineering. New York: McGraw-Hill; 1978.

3. Kalogirou S. Solar water heating in Cyprus. Current status of technology and problems. Renewable Energy 1997; 10:107-12

4. Schweiger H., Mendes J.F., Benz N., Hennecke K., Prieto G., Gusi M., Goncalves H. The potential of solar heat in industrial processes. a state of the art review for Spain and Portugal. Proceedings of Eurosun'2000 Copenhagen, Denmark on CDROM; 2000.

5. Kalogirou $\mathrm{S}$. The potential of solar industrial process heat applications. Appl Energy. №76, 2003. p.337-61. 6. Norton B. Solar process heat: distillation, drying, agricultural and industrial uses. Proceedings of ISES Solar World Congress, Jerusalem, Israel on CD-ROM, Jerusalem, Israel; 1999.

7. Hoshimov, F.A., Bakhadirov, I.I., Erejepov, M., Djumamuratov, B. (2019) Development of method for normalizing electricity consumption E3S Web Conf 139 doi:10.1051/e3sconf/201913901074
8. Benz N., Gut M., Rub W. Solar process heat in breweries and dairies. Proceedings of EuroSun 98, Portoroz, Slovenia on CD-ROM; 1998.

9. Safarov J.E., Sultanova Sh.A. Kinetic regulations of the drying process of drug plants. // International Journal of Innovations in Engineering Research and Technology. ISTC-2K20. 2020. P.95-98.

10. Sultanova Sh.A. Ispol'zovanye gelio vodonagrevatel'noy ustanovky dlya sushky lekarstvennikh rastenii. IX Mezhdunarodnaya nachnopraktycheskaya konferentsya «Naukovi zdobutki u virishenni aktual'nikh problem virobnitstva ta pererobki sirovini, standartyzatsiyi i bezpeki prodovol'stva». Kiev, 2020. -C. 231-232.

11. Sultanova Sh.A. Effektivnost' primenenya solnechnogo kollektora $\mathrm{v}$ sushilkakh pry sushke rastitel'nogo sir'ya. IX Mezhdunarodnaya nachnoprakticheskaya konferentsyya «Naukovi zdobutki u virishenni aktual'nykh problem virobnitstva ta pererobki sirovini, standartyzatsiyi i bezpeki prodovol'stva». Kiev, 2020. -C.229-230.

12. Sultanova Sh.A., Safarov J.E. Experimental study of the drying process of medicinal plants. // International Journal of Psychosocial Rehabilitation (Scopus). Volume 24, Issue 8. 2020. P.1962-1968. DOI: $10.37200 /$ IJPR/V24I8/PR280216

13. Safarov J.E., Sultanova Sh.A., Dadayev G.T. Development of solar accumulating drying equipment based on the theoretical studies of solar energy accumulation. Energetika. Proc. CIS Higher Educ. Inst. and Power Eng. Assoc. V. 63, No2., 2020. pp. 174 192.

14. Safarov J.E., Sultanova Sh.A., Beraat Özçelik, Gürbüz Güneş. Programmnoye obespecheniye matematicheskoy modeli tekhnologii kachestvennoy pererabotki lechebnykh rasteniy DGU 07724 ot 12.02.2020 г.

15. Safarov J.E., Sultanova Sh.A., Aït-Kaddour A., Dadayev G.T. Research technology for drying medicinal plants. // International Journal of Advanced Science and Technology. Vol.29, №9s. 2020. pp.58195822 .

16. Sultanova Sh.A. Effektivnost' primenenyya solnechnoho kollektora $\mathrm{v}$ sushilkakh pri sushke rastytel'nhoho sir'ya. IX Mezhdunarodnaya nachnopraktycheskaya konferentsyya «Naukovi zdobutki u vyrishenni aktual'nykh problem virobnitstva ta pererobki sirovini, standartyzatsiyi i bezpeki prodovol'stva». Kiev, 2020. -C. 229-231.

17. Stevens R.. 2016, Energy \& Environment Option Lead Associate Professor, Rochester Institute of Technology, private communication.

18. Van Decker G.W.E., Hollands K.G.T., Brunger A.P. Heat-exchange relations for unglazed transpired solar collectors with circular holes on a square or triangular pitch. Sol. Energy, vol. 71, no. 1, 2001. pp. $33-45$. 